\title{
Medidas cautelares innominadas en procesos de competencia desleal y su capacidad de afectación a los consumidores
}

Precautionary Measures in Unfair Competition and their Potential Effect on Consumers

\author{
José Fernando Sandoval Gutiérrez ${ }^{\text {a }}$ \\ Universidad de los Andes, Colombia \\ jfsg86@gmail.com \\ ORCID: https://orcid.org/0000-0001-8220-8363
}

DOI: https://doi.org/10.11144/Javeriana.vj69.mcip

Recibido: 10 Septiembre 2019

Aceptado: 29 Octubre 2019

Publicado: 30 Diciembre 2020

\section{Resumen:}

En este artículo de reflexión se plantea el posible impacto que pueden tener sobre los consumidores, como beneficiarios de la libre competencia económica, las medidas cautelares innominadas decretadas en procesos judiciales de competencia desleal. Para ello, se utiliza un método inductivo-deductivo y trabajo de campo en el área judicial: se hace una revisión de lo que ha expresado la Corte Constitucional de Colombia y la doctrina acerca de los beneficios que se esperan de la libre competencia económica y eso es confrontado posteriormente con decisiones cautelares proferidas por la autoridad colombiana especializada en asuntos de competencia desleal, a fin de establecer la posible afectación que se puede llegar a generar con ese tipo de decisiones.

Palabras clave: libre competencia económica, competencia desleal, mercado, medidas cautelares innominadas, consumidor.

\section{Abstract:}

This reflection article approaches the possible impact that precautionary measures on unfair competition matters may have on consumers, as beneficiaries of free economic competition. To do so, inductive-deductive research material is used along with judicial fieldwork. This article reviews the Colombian Constitutional Court's decisions and doctrine about the benefits expected from free economic competition, to be later confronted with precautionary measures taken by the Colombian authority specialized in unfair competition matters to establish the possible impact that can be generated with such decisions.

Keywords: free economic competition, unfair competition, market, innominated precautionary measures, consumer.

\section{Introducción}

La "medida cautelar" es una herramienta procesal que presta un importante servicio al proceso judicial en beneficio del reclamante de justicia. Esta, bajo la modalidad de "innominada”, otorga al juez de competencia desleal un amplio margen de discrecionalidad que al mismo tiempo debe estar acompañado de un amplio grado de acierto. Lo anterior, en tanto que una decisión de ese tipo podría dar lugar a diferentes formas de afectación, que trasciendan no sólo en la esfera particular de la persona que es demandada, sino también en la de los consumidores, quienes, a pesar de eso, están por fuera del interés del proceso.

Ciertamente, ya que una sentencia favorable a las pretensiones no es necesariamente la consecuencia de la presentación de una demanda, es posible que el sujeto pasivo de una medida cautelar no sea, a fin de cuentas, vencido en el juicio de competencia desleal. Si esto último ocurre, podría haber lugar a una situación en la que, aunque el demandado obtuvo una victoria en términos procesales, también sufrió una serie de daños por cuenta del decreto de la medida cautelar, y adicionalmente, dicha decisión dejó a su paso una serie de afectaciones colectivas en las que nadie pensó.

Esta situación problemática permite formular el siguiente planteamiento que será defendido a lo largo de este artículo: las medidas cautelares innominadas decretadas en procesos judiciales por actos de competencia desleal pueden causar no solo daños de alcance particular al sujeto pasivo de la medida, también tienen la

Notas de autor

\footnotetext{
${ }^{a}$ Autor de correspondencia. Correo electrónico: jfsg86@gmail.com
} 
capacidad de afectar colectivamente a los consumidores como beneficiarios de la libre competencia económica debido a la posible frustración de los beneficios que de esta se esperan. No obstante lo anterior: a) los consumidores, pese a ser beneficiarios de la libre competencia económica, no son llamados a que intervengan en el proceso, b) para el decreto de medidas cautelares innominadas en procesos judiciales por actos de competencia desleal, no es requisito analizar la posible afectación a los consumidores, y c) el Código General del Proceso (en adelante CGP) no contempla herramientas de garantía para el pago de daños a favor de los consumidores, pues las cauciones no los benefician.

El objetivo de este artículo es plantear una crítica a la institución de las medidas cautelares, especialmente las innominadas, lo cual permitirá reflexionar sobre la posible insuficiencia de esta figura jurídica en materia de competencia desleal. Es importante precisar que el alcance es estrictamente teórico, pues no pretende demostrar los efectos económicos que en la práctica se han generado con el decreto de medidas cautelares, sino plantear la posible afectación que estas podrían generar partiendo de lo que la Corte Constitucional de Colombia y la doctrina han enseñado acerca de los beneficios que se esperan del régimen de libre competencia económica.

\section{La libre competencia económica y sus beneficios}

La libre competencia económica es un principio rector de la actividad económica en Colombia, aspecto que queda claro con el artículo 333 de nuestra constitución. Sobre este derecho y para efectos del presente artículo, resulta de gran trascendencia resaltar que la libre competencia funciona en beneficio, de un lado, de los empresarios, y del otro, de toda la comunidad. Sobre este punto, afirma Gómez que,

\footnotetext{
"si bien la competencia se genera en el hecho de tener los distintos participantes la misma pretensión, que consiste en tener el favor de la clientela, tal competencia no puede reducirse al criterio utilitarista de la simple obtención de resultados económicos, ni observarse ni analizarse con este criterio cerrado e individualista, pues va mucho más allá, en cuanto con la misma se satisfacen necesidades sociales y, en consecuencia, ella involucra el interés de sus destinatarios, o sea, el de los consumidores".
}

Este aspecto puede confirmarse al consultar la Sentencia C-616 de 2001 en la que la Corte Constitucional explicó que,

"La competencia es un principio estructural de la economía social del mercado, que no sólo está orientada a la defensa de los intereses particulares de los empresarios que interactúan en el mercado, sino que propende por la protección del interés público, que se materializa en el beneficio obtenido por la comunidad de una mayor calidad y unos mejores precios de los bienes y servicios que se derivan como resultado de una sana concurrencia". ${ }^{2}$

Es así como puede afirmarse que la libre competencia económica se concibe desde una doble dimensión, pues es un derecho individual y al mismo tiempo es un derecho colectivo. Desde su dimensión individual debe generar al empresario la posibilidad de obtener lucro a partir de su actividad económica, y desde su dimensión colectiva - la de interés para este trabajo - debe generar beneficios al consumidor con bienes y servicios de mejor calidad, con mayores garantías y a un precio real y justo ${ }^{3}$. Para explicar esto último, la Corte Constitucional ha señalado que los compradores son los que en mayor medida se benefician en los mercados que funcionan con condiciones competitivas. Lo anterior, por cuanto en estos mercados hay una permanente búsqueda de la eficiencia de los oferentes, lo que supone que los compradores se verán beneficiados por reducción en los precios o mejora en la calidad de lo que compran ${ }^{4}$. Font Galán, refiriéndose a un mercado como el nuestro, señala que

“existe una competencia entre productores en pugna por alcanzar una expansión mayor en el mercado de sus bienes y servicios, mejorar la producción, la distribución y la publicidad, ofrecer las condiciones más favorables y ventajas especiales, ampliar el círculo de la clientela, aumentar el volumen de ventas e incrementar así las ganancias; paralelamente existe también una 
competencia directa entre consumidores al objeto de conseguir, en las condiciones más ventajosas ofrecidas, aquellos bienes económicos limitados que satisfacen mejor sus necesidades" 5 .

Por ello, la pluralidad de participantes que ofrecen productos y servicios es un elemento medular cuando se habla de libre competencia económica. Para la Corte Constitucional, la protección de la libre competencia económica debe impulsar o promover la existencia de una pluralidad de oferentes que hagan efectivo el derecho a la libre elección de los consumidores ${ }^{6}$. Aspecto último sobre el que Nihoul señala que

"gracias a la competencia, los consumidores tienen la posibilidad de dirigirse a varios interlocutores, pudiendo ser más o menos numerosos según el mercado. Los consumidores podrán escoger, entre las diferentes ofertas, aquella que mejor responde a sus necesidades".

En suma, tratándose de libre competencia económica, es fundamental la pluralidad de oferentes, ya que en la medida que existan más competidores con más productos y servicios, existirán mayores beneficios para los consumidores, pues tal circunstancia traerá como resultado productos y servicios de superior calidad y a mejores precios.

\section{El régimen de competencia desleal en Colombia}

Colombia cuenta con una regulación especial en materia de competencia desleal que se encuentra establecida en la Ley 256 de 1996. Con este régimen, el legislador se propuso garantizar la libre y la leal competencia económica, así como lo expresa el artículo 1 al señalar que, "sin perjuicio de otras formas de protección, la presente ley tiene por objeto garantizar la libre y leal competencia económica, mediante la prohibición de actos y conductas de competencia desleal, en beneficio de todos los que participen en el mercado".

En relación con el objeto que se pretende proteger con este régimen afirma Massaguer que,

"la represión de la competencia desleal tiene por objetivo el aseguramiento de la funcionalidad de la competencia económica (mercados altamente competitivos y transparentes), pero también, y al mismo tiempo, la salvaguardia de la libertad individual al ejercicio de la actividad económica en el mercado, de la libertad de elección de los consumidores y del derecho de todos a la formación de las relaciones de mercado según el modelo operativo propio de la competencia económica”. ${ }^{8}$

Así, considerando que la ley de competencia desleal (LCD) colombiana tiene como uno de sus propósitos garantizar la libre competencia económica, puede afirmarse que su aplicación debería llevar a que el mercado se torne eficiente y de esa manera provea grandes beneficios a los consumidores, en la medida que se logre la existencia de productos y servicios de mejor calidad y a mejores precios gracias a ella.

Para cumplir este propósito, la LCD reprocha ciertos comportamientos, siempre y cuando se realicen en el escenario del mercado y tengan finalidad concurrencial, esto es, que estén encaminados a mantener o incrementar la participación en el mercado de quien ejecuta la conducta o de un tercero' 9 . Tales comportamientos se encuentran enlistados dentro de la misma LCD, dado que el legislador en esta materia elaboró la descripción de diversas modalidades de conducta que ${ }^{10}$, en caso de ser ejecutadas por algún participante del mercado, son susceptibles de reproche por parte de la autoridad.

\section{Medidas cautelares innominadas en el procedimiento civil colombiano}

Las medidas cautelares son una herramienta otorgada por el derecho procesal, que permiten al demandante tener un remedio anticipado de aquella inconformidad que lo motivó a poner en funcionamiento el aparato jurisdiccional. Villamil explica que: 
"La medida cautelar como instrumento para asegurar la eficacia de las decisiones judiciales, inscribe su importancia en los derechos fundamentales de acceso a la administración de justicia, debido proceso y vigencia del ordenamiento".

De ahí que este remedio judicial sea indispensable en el ordenamiento jurídico para garantizar la tutela judicial efectiva.

Nuestra tradición jurídica muestra una preferencia por las medidas cautelares taxativas muy bien definidas y determinadas en la ley, aunque algunas normas aisladamente han permitido al juez decretar medidas no taxativas o innominadas ${ }^{12}$. Actualmente, con ocasión de la expedición de la Ley 1564 de 2012 (CGP.), dichas medidas innominadas adquirieron un carácter transversal que permite su utilización al interior de todos los procesos declarativos, propósito que se cumple en el artículo $590^{13}$. Sobre este tipo de cautelares, afirma Meroi que "la exigencia constitucional de tutela jurisdiccional impone la previsión de una medida cautelar atípica dirigida a neutralizar todos los 'peligros en la demora' no previstos en las medidas cautelares típicas" ${ }^{14}$. Pues bien, las medidas cautelares de tipo innominado son aquellas cuyo contenido se encuentra indeterminado para que sea la autoridad judicial quien se encargue de elaborar aquella que resulte más adecuada para el caso específico que en ese momento se encuentre resolviendo. Por ello, las características de la medida cautelar que se decrete dependerán de las características puntuales de cada caso. En ese sentido, el juez desempeña el papel de un "artesano jurídico" 15 al elaborar la orden provisional más adecuada para la protección anticipada de los derechos del demandante.

Para desarrollar esa compleja labor, el artículo 590 del CGP ofrece una amplia redacción que incluye lo que he optado por denominar "criterios orientadores de la función judicial para el decreto de medidas cautelares innominadas y su adecuado diseño" ${ }^{16}$, los cuales no aparecían con tanto nivel de detalle en las normas que antecedieron al CGP. Dichos criterios son la legitimación o interés, la amenaza o vulneración del derecho, la apariencia de buen derecho (fumus boni iuris), la necesidad (periculum in mora), la efectividad y la proporcionalidad.

\section{Legitimación o interés}

Teniendo en cuenta que en Colombia las medidas cautelares no gozan de un proceso independiente, debiendo estar siempre atadas a otro trámite que sí es el principal, puede afirmarse que quien puede solicitarlas es aquel que cuente con legitimación dentro del proceso principal. En este mismo sentido, afirma García Sarmiento que "la legitimación activa le corresponde al titular del derecho sustancial que requiere la cautela"17.

\section{Amenaza o vulneración del derecho}

Al momento de decidir sobre la solicitud de medidas cautelares, el juez debe establecer si el derecho cuya protección se reclama ya fue afectado, o si existe la inminencia de que esa afectación se concrete, pues en ambos casos resultaría posible decretar la medida cautelar. De hecho, la orden cautelar que se elabore para un caso concreto puede, en buena medida, variar si no se ha sobrepasado el escenario de la amenaza. En relación con esta última, afirma Rocco que

"peligro, considerado como posibilidad de un daño, es, por tanto, la potencia o la idoneidad de un hecho para ocasionar el fenómeno de la pérdida o disminución de un bien, o el sacrificio, o la restricción, de un interés, sea éste tutelado o la forma de un derecho subjetivo, o en la de un interés jurídico". ${ }^{18}$

Lo anterior es de gran relevancia en asuntos de competencia desleal, por cuanto en este tipo de procesos es posible formular pretensiones de tipo preventivo, conforme al numeral 2 del artículo 20 de la LCD. 


\section{Apariencia de buen derecho (fumus boni iuiris)}

Para decidir sobre la procedencia de la medida cautelar, el juez debe llevar a cabo un análisis de los hechos y de las pruebas con las que se cuentan hasta ese momento a fin de lograr cierto grado de convencimiento acerca de lo reclamado por el accionante. Ese grado de convencimiento se limita únicamente al de verosimilitud por encontrarse en una etapa apenas preliminar de la actuación, mientras que el grado de certeza ha de alcanzarse únicamente en la sentencia, acto procesal en el que el caso finalmente se resuelve. Al respecto, señala Pérez que "El fumus boni iuris se puede definir como la obligación de acreditar prima facie que la pretensión que se pretende asegurar va a ser estimada por el órgano jurisdiccional" ${ }^{19}$. Por ello, al hacer el estudio sobre la apariencia de buen derecho, el juez, aunque no tendrá certeza aún sobre el fondo del proceso, si habrá de prever que, al momento de dictar sentencia, esta acogerá las pretensiones de la demanda. En relación con lo dicho, enseña Calamandrei que:

"Por lo que se refiere a la investigación sobre el derecho, la cognición cautelar se limita en todos los casos a un juicio de
probabilidades y de verosimilitud. Declarar la certeza de la existencia del derecho es función de la providencia principal: en
sede cautelar basta que la existencia del derecho aparezca verosímil, o sea, para decirlo con mayor claridad, basta que, según
un cálculo de probabilidades, se pueda prever que la providencia principal declarará el derecho en sentido favorable a aquel
que solicita la medida cautelar".

\section{Necesidad (periculum in mora)}

Los procesos judiciales normalmente están compuestos de una serie de etapas cuyo agotamiento implica una inversión razonable de tiempo. Dicha demora, aunque sea normal, es motivo de preocupación por el legislador interesado en garantizar la tutela judicial efectiva. Por ello, como lo señala Redenti,

"sabiamente se preocupa la ley por el peligro, en muchos casos manifiesto e innegable, de que las providencias de tutela
jurisdiccional (sanción) civil que ella conmina o prevé, lleguen a aplicación demasiado tarde, porque la vía para llegar a ella
es demasiado larga y no sin tropiezos. En consideración a ello se han introducido las reglas, que ya conocemos, en virtud
de las cuales los efectos de las providencias finales de fondo se hacen remontar en lo posible al momento de la demanda
judicial (curso de los intereses, resarcimiento de los daños sobrevenidos en pendencia de Litis, efectos de la transcripción de
la citación, etc.). Pero todo esto no sirve ya de nada, si entretanto ... se han escapado los bueyes; es decir, si no se encuentra
ya, por así decirlo, la materia prima sobre la cual actuar de hecho la sanción" "21.

En Colombia existe un término máximo para que el juez de primera o única instancia profiera sentencia en los procesos que se tramitan bajo las reglas del CGP ${ }^{22}$. Dicho término no puede ser superior a un año y puede ser prorrogado de manera excepcional hasta por seis meses más.

La demora normal del proceso puede implicar para el demandante el agravamiento de su situación a tal punto que ya sea demasiado tarde cuando la sentencia se profiera, aspecto que justifica la necesidad de que exista la facultad de proferir medidas cautelares. En línea con lo anterior, afirma Couture que "las providencias cautelares cautelan contra la lentitud del proceso. Previenen tan solo el riesgo de que la demora en llegar hasta la sentencia no haga ilusorio el fin del proceso" ${ }^{23}$. Es por ello que el juez, al momento de decidir sobre la procedencia de las medidas cautelares, debe verificar si la demora normal del proceso puede agravar la actual situación del accionante. De ser así, se justifica adoptar una decisión encaminada a proteger sus derechos de manera anticipada y por esa vía evitar que la sentencia sea ilusoria. 


\section{Efectividad}

Verificado el cumplimiento de los criterios antes mencionados, el juez procederá a decretar la medida cautelar. Para ello, debe tener en cuenta que la finalidad de la institución cautelar está encaminada a garantizar que al momento de dictar sentencia sean protegidos los derechos del demandante y de esa manera esta no se convierta en un acto procesal ilusorio, lo que impone proferir una orden cautelar que sirva para dicho propósito. En palabras de Ortells Ramos, la efectividad "supone también que se proteja la sentencia frente a los riesgos que impidan que la ejecución se desarrolle en condiciones de plena utilidad para el que acabe por ser reconocido como titular del derecho" ${ }^{24}$. Vale agregar que, a la hora de diseñar una medida, el funcionario judicial debe proceder con precaución ya que, como se verá en el punto siguiente, la orden que se profiera no solo debe ser efectiva, también debe atender a la proporcionalidad.

\section{Proporcionalidad}

Recordemos que tratándose de medidas cautelares innominadas el juez cumple la labor de un "artesano jurídico". En esa labor de diseño de la medida cautelar más ajustada al caso, el operador de justicia no puede perder de vista que, a pesar de la apariencia de buen derecho, hay aún un proceso que agotar y que su resultado puede ser incluso favorable al demandado. Por ello, la orden cautelar debe procurar no solamente proteger los derechos de la parte accionante, sino que además debe evitar gravar en exceso al demandado, quien aún podría tener una victoria. Al respecto, afirma Forero que la medida cautelar

"según lo pedido y cuantificado en la demanda, debe ser razonable, acompasada con el monto de la pretensión, para que no resulte exagerada. El juez debe ponderarla decretando aquella cautela que se ajuste al caso concreto, sin olvidar que el demandado no ha sido condenado, y que a la vez sirva para materializar la pretensión en caso de que llegare a ser vencido". 25

Considerando que el escenario que interesa en el presente artículo es el de las medidas cautelares innominadas decretadas en procesos judiciales en los que se debate sobre la posible comisión de actos de competencia desleal, es necesario agregar que el artículo 590 del CGP debe aplicarse de manera armónica con el artículo 31 de la LCD que contiene también normas relativas a medidas cautelares, pero aplicables exclusivamente a procesos de competencia desleal.

Detallado este escenario, se mostrará cómo las medidas cautelares innominadas podrían llegar a frustrar los beneficios que se esperan de la libre competencia económica.

\section{Sobre cómo las medidas cautelares innominadas decretadas en procesos judiciales de competencia desleal podrían frustrar los beneficios que se esperan de la libre competencia económica}

Recordemos que la LCD tiene como objeto, además de garantizar la leal competencia, garantizar la libre competencia económica. Esto pretende lograrse en beneficio de todos los que participan en el mercado, es decir, que dentro de sus beneficiarios se encuentran no solamente los empresarios, sino también los consumidores.

Partiendo de lo anterior, es posible plantear, al menos de forma teórica, que las decisiones tomadas en el desarrollo de un proceso judicial por actos de competencia desleal pueden trascender la esfera particular de las partes vinculadas al proceso hasta llegar a la esfera de los consumidores, en tanto que, se insiste, son también beneficiarios del régimen según lo señala la misma ley. 
Ahora bien, la trascendencia hasta esa esfera es el resultado de la decisión del juez de corregir una situación anormal y reprochable como lo es la comisión de un acto de competencia desleal, lo que, al menos en principio, debe redundar en beneficio del consumidor como cuando se retira del mercado un producto que lo está confundiendo. Sin embargo, también puede ocurrir que esa trascendencia tenga efectos negativos al mismo tiempo, a pesar de la corrección y reproche que procura hacer la LCD en beneficio de "todos los que participan en el mercado".

A fin de corroborar este primer nivel del planteamiento, fueron revisados cien autos que acogieron solicitudes de medidas cautelares innominadas dentro de procesos judiciales por actos de competencia desleal $^{26}$. Dichas providencias corresponden a los años 2012 a 2017, teniendo en cuenta que se dispuso el 1 de octubre de 2012 como fecha de inicio de vigencia del artículo 590 del CGP. A continuación, veremos solamente tres ejemplos de providencias cuya trascendencia puede ser negativa para los consumidores:

1. En un primer caso, la autoridad analizó un conflicto entre dos sociedades comerciales que participaban en el mercado de los útiles escolares y de oficina. Tras verificarse preliminarmente la comisión del acto desleal de confusión, mediante Auto No. 1269 de 25 de enero de 2013, se ordenó a la demandada retirar del mercado los elementos de oficina y útiles escolares que estaba comercializando ${ }^{27}$.

2. Un segundo caso muestra un conflicto en el que una sociedad comercial demandó a dos personas naturales (exsocios) y una persona jurídica (ex distribuidora). Una vez el juez verificó la presunta comisión del acto desleal de confusión, mediante Auto No. 3712 de 28 de febrero de 2013, se ordenó a los demandados abstenerse de comercializar su endulzante natural sin calorías en diferentes presentaciones y retirar aquellos que ya estuvieren circulando en el mercado ${ }^{28}$.

3. El tercer caso corresponde a un conflicto entre dos sociedades comerciales participantes del mercado de leche en bolsa. Verificada por parte del juez la presunta comisión del acto desleal de confusión, mediante Auto No. 12433 de 20 de marzo de 2014, se ordenó a la demandada retirar del mercado la leche en bolsa que se encontraba comercializando ${ }^{29}$.

Estas decisiones judiciales, así como otras proferidas por la misma entidad especializada ${ }^{30}$, tienen en común que en todas ellas se hace exclusión de algún producto del mercado. En efecto, las órdenes impartidas por el juez están encaminadas, por un lado, a prohibir que se continúe con la comercialización de los productos, y por otro, a ordenar que se retiren aquellos que se hubieran puesto a disposición de los consumidores, es decir, aquellos que ya estuvieran en circulación.

Corolario de lo anterior, una vez cumplida la orden cautelar proferida por el juez, los consumidores tendrían una opción menos a la cual acceder para la satisfacción de sus necesidades — la ofrecida por el demandado-, pues los productos habrían sido retirados del mercado y dejarían de ser comercializados, al menos durante el tiempo de duración del proceso.

Ahora bien, teniendo en cuenta cuáles son los beneficios que se esperan de un sistema de libre competencia económica como el nuestro de acuerdo a lo explicado por la Corte Constitucional y la doctrina, es posible llegar a la primera conclusión de este trabajo: una medida cautelar innominada decretada dentro de un proceso judicial por actos de competencia desleal podría frustrar los beneficios que se esperan de la libre competencia económica y, por tanto, afectar a uno de sus beneficiarios, esto es, a los consumidores.

Para explicarlo recordemos que, tratándose de libre competencia económica, es de gran importancia la pluralidad de oferentes y con ellos la pluralidad de productos y servicios, ya que gracias a esa pluralidad se garantiza la libre elección de los consumidores y se promueve la existencia de productos y servicios de mejor calidad y a un precio real y justo. Partiendo de dicho supuesto, es posible afirmar que en la medida en que se excluyan oferentes, o se excluyan productos y servicios del mercado vía orden cautelar, podría haber una frustración de los beneficios que se esperan de un sistema de libre competencia económica, en tanto que el 
efecto logrado sería contrario al que se produce gracias a la pluralidad. Dicho de otro modo, la ausencia de competidores o la ausencia de productos y servicios como resultado de la exclusión que produce la orden cautelar podría implicar una menor calidad de productos y servicios en el mercado, así como precios menos favorables para los consumidores.

Sin embargo, aun con la gravedad que sugiere esta afirmación, no podemos ignorar que, por lo menos en principio, la afectación referida se causa de manera legítima en tanto que es consecuencia de una decisión legítima del estado que se toma con ocasión de la facultad de administrar justicia. En tal sentido, la frustración de los beneficios que se esperan de la libre competencia económica es una carga que deben soportar los consumidores y por la cual no podrían buscar un resarcimiento. Considérese además que la misma sería el resultado de corregir el comportamiento desleal de un empresario de manera anticipada, que podría estar, por ejemplo, confundiéndolos o engañándolos, y desde ese punto de vista la decisión cautelar está encaminada también a beneficiarlos.

Llegados a este punto, es importante dejar claro al lector que la posible frustración de los beneficios que se esperan de la libre competencia económica, tal como está planteada en este escrito, no se refiere a que se haya hecho una verificación real en el mercado a fin de establecer con certeza que tales efectos negativos se produjeron en los casos que fueron referenciados. Lo que aquí se plantea es la posibilidad de que eso ocurra, partiendo para ello de los beneficios que se esperan de la libre competencia económica según lo explicado por la Corte Constitucional y la doctrina, y se le aplican a las ordenes proferidas a instancia cautelar por la entidad especializada, lo que lleva a las conclusiones respectivas desde un punto de vista estrictamente teórico y no fáctico.

\section{Sobre la problemática que se genera con este tipo de decisiones cuando la sentencia no acoge las pretensiones de la demanda}

Pese a la aludida carga que deben soportar los consumidores, la circunstancia explicada en el título anterior puede tener un matiz distinto si a pesar de haberse decretado la medida cautelar el juez, al momento de dictar sentencia, desestima las pretensiones de la demanda. Esta no es una posibilidad que se encuentre descartada, aun cuando se haya acogido la solicitud cautelar, debido al carácter apenas provisional de ese tipo de medidas y de estar fundamentadas en la apariencia de buen derecho y no en la certeza de este. Piénsese, por ejemplo, en que a lo largo de la etapa probatoria el juez encontró elementos de juicio suficientes - elementos con los que no contaba al momento de decidir sobre la procedencia de la medida cautelar- para considerar que las circunstancias particulares del mercado analizado y las características de los consumidores que a él concurrían, permitían descartar la existencia del acto de competencia desleal.

En caso de presentarse una situación como esta, es posible que al finalizar el proceso nos encontremos, al menos, frente a una doble afectación, pero en la etapa definitiva y no en la provisional como ocurre en la etapa cautelar. De un lado, la posible afectación que sufre el sujeto pasivo de la medida cautelar, y del otro, la que posiblemente sufren los consumidores como destinatarios de los beneficios que genera la libre competencia económica.

A continuación, se expondrán brevemente dos casos adelantados por la entidad colombiana especializada en materia de competencia desleal. En ambos fueron decretadas medidas cautelares de aquellas con el potencial de frustrar los beneficios que se esperan de la libre competencia económica y, pese a ello, en los dos casos la sentencia desestimó las pretensiones de la demanda. A partir de tal situación, de un lado de manera hipotética se identificarán los posibles daños que pudo sufrir el sujeto pasivo de la medida, y del otro, los daños a los consumidores. 


\section{Primer caso: exclusión de un participante del mercado}

Este caso involucra a personas naturales y jurídicas participantes del mercado de la comercialización de tintas para la industria gráfica. En la etapa cautelar, la autoridad encontró que el empresario demandado, siendo socio de la sociedad comercial demandante, creó otra dedicada a lo mismo y logró beneficiarla, pues los clientes y proveedores fueron confundidos ya que pensaban estar negociando con la demandante, cuando en realidad lo hacían con aquella creada de manera posterior por el demandado. Por ello, mediante Auto No. 38303 de 13 de diciembre de $2013^{31}$, se decretó una medida cautelar en la que se ordenó al empresario abstenerse de participar por sí mismo o por interpuesta persona, ya fuera en interés personal o de terceros, en actividades que implicaran competencia con la sociedad demandante. A pesar de lo anterior, una vez agotadas las etapas correspondientes del proceso, en audiencia celebrada el día 4 de agosto de $2015^{32}$ se profirió sentencia en la que fueron desestimadas las pretensiones de la demanda.

\section{Primer nivel de afectación}

En este caso, un primer nivel de afectación tiene que ver con los posibles daños sufridos por el empresario debido a la medida cautelar que le fue impuesta. Así, teniendo en cuenta que se le prohibió participar en el mercado a través de actividades que implicaran competencia con la demandante, es posible que haya sufrido un lucro cesante debido a que no pudo percibir ingresos derivados de la actividad económica específica debatida en el proceso durante el tiempo que estuvo vigente la medida cautelar. Por otro lado, supongamos que este empresario había adquirido obligaciones con empleados y clientes a quienes tuvo que indemnizar debido a que incumplió sus obligaciones contractuales por la imposibilidad de ejercer la actividad comercial, caso en el cual habría sufrido un daño emergente ${ }^{33}$.

\section{Segundo nivel de afectación}

En el mismo caso, el segundo nivel de afectación correspondería a aquel que podrían sufrir los consumidores debido a la posible frustración de los beneficios esperables de la libre competencia económica. En efecto, con la orden cautelar proferida se logró la exclusión de un participante del mercado mediante la prohibición de ejercer actividades comerciales que implicaran competencia con la demandante. En ese sentido, debido a la medida cautelar, el mercado de interés para el proceso se vio modificado en cuanto al número de oferentes, pues en adelante tendría uno menos. Esta circunstancia, como antes se explicó, puede redundar en perjuicio de los consumidores.

\section{Segundo caso: exclusión de productos del mercado}

En este caso se enfrentaron dos sociedades participantes del mercado de productos alimenticios preparados. La autoridad pudo establecer, en la etapa cautelar, que la demandada se estaba identificando en el mercado usando una expresión muy similar a las marcas utilizadas por la demandante. Lo anterior, a pesar de que la demandada era titular de una marca distinta y, sin embargo, optó por resaltar en los empaques de sus productos algunos elementos - similares a los de la marca de la demandante- que finalmente llevaban a causar confusión entre los consumidores. Como consecuencia de esa situación, mediante Auto 3689 de 28 de febrero de $2013^{34}$, se ordenó a la demandada retirar de los circuitos comerciales los productos lácteos que se encontraba comercializando. Posteriormente el juez resolvió negar las pretensiones de la demanda en audiencia llevada a cabo el día 18 de diciembre de $2014^{35}$, pese a que se había decretado la medida. 


\section{Primer nivel de afectación}

$\mathrm{Al}$ igual que en el primer caso, un primer nivel de afectación está relacionado con los daños posiblemente sufridos por la compañía destinataria de la orden cautelar. En este caso, debido a que los productos que la demandada tuvo que retirar son perecederos, es posible que haya perdido la posibilidad de obtener una ganancia a partir de la venta de los mismo, en esa medida habría sufrido un lucro cesante. Adicionalmente, el retiro de los productos que ya se encontraban circulando puede haberle implicado una recompra de los mismos, junto con todos los gastos que pueden acompañar dicho procedimiento, como podrían ser los de transporte, de bodegaje, entre otros, todo lo cual representa un daño emergente.

\section{Segundo nivel de afectación}

De igual forma que en el primer caso, el segundo nivel de afectación es aquel en el que pueden ser perjudicados los consumidores con ocasión de la posible frustración de los beneficios de la libre competencia económica. Para explicarlo, debe resaltarse que mediante la orden cautelar fueron excluidos algunos productos lácteos del mercado. En ese orden de ideas, con esta medida fue eliminada una de las opciones de los consumidores para satisfacer su necesidad en lo que respecta al consumo de este tipo de productos.

Tal como lo muestran las decisiones mencionadas, es posible que una medida cautelar innominada decretada dentro de un proceso judicial por actos de competencia desleal deje a su paso una doble afectación. De un lado, aquella de alcance particular que sufre el sujeto pasivo de la medida cautelar, y, del otro, aquella que afecta a los consumidores como beneficiarios colectivos de la libre competencia económica.

Esta doble afectación, que en principio debía ser soportada en tanto que fue el resultado de una decisión legítima del poder judicial del Estado, se hace susceptible de resarcimiento cuando la sentencia desestima las pretensiones del demandante pues, bajo ese supuesto, ni los empresarios, ni los consumidores tienen que soportar la consecuencia dañosa producida por la orden cautelar y, por tanto, es necesario que sus derechos sean restablecidos al momento anterior al decreto de la medida.

Sin embargo, en un proceso judicial que se desarrolla inter partes, la afectación que sufren los consumidores parece no ser de interés para las normas procesales, ni para las normas especiales que regulan los asuntos relativos a la competencia desleal.

\section{Sobre la ausencia de mecanismos procesales en la ley de competencia desleal y en el código general del proceso frente a la posible frustración de los beneficios de la libre competencia económica}

A pesar de la importancia que tiene esta circunstancia puesta en evidencia, especialmente por el hecho de que las medidas cautelares innominadas tengan la capacidad de trascender la esfera particular de las partes vinculadas al proceso hasta llegar a afectar a los consumidores como beneficiarios de las ventajas que reporta la libre competencia económica, esto no parece ser de interés de la LCD ni de las disposiciones adjetivas contenidas en el CGP, pues en ellas no existen mecanismos que permitan afrontar una situación de esta naturaleza, como pasa a explicarse a continuación. 


\section{En los procesos judiciales por actos de competencia desleal que se desarrollan entre empresarios, no existen normas especiales sobre intervención que garanticen la comparecencia de los consumidores al proceso}

Ninguno de los artículos de la Ley 256 de 1996 establece reglas especiales sobre la necesidad de que se vincule al proceso a los consumidores cuando el litigio se desarrolla entre empresarios. Lo anterior, a pesar de ser los consumidores beneficiarios la libre competencia económica. En tal aspecto, las normas que se refieren a los posibles intervinientes en este tipo de asuntos son únicamente aquellas de la LCD que tratan sobre la legitimación activa y pasiva, y las generales consagradas en el CGP. relativas a la intervención de partes y terceros que son transversales a todos los procesos.

En lo relativo a las normas especiales sobre legitimación, recordemos que el artículo 21 de la LCD la otorga a quien participe en el mercado o tenga la intención de hacerlo, quien adicionalmente debe haber visto afectados o amenazados sus intereses económicos por un acto de competencia desleal. Se debe recordar que también existen unas formas especiales de legitimación consagradas en el mismo artículo 21 de la LCD.

Así, la norma de legitimación activa permite que consumidores individualizados presenten demandas por actos de competencia desleal, siempre y cuando sus intereses económicos estuvieren siendo afectados por la conducta desleal, caso en el cual actuarían en el proceso, cada uno de ellos, en calidad de parte demandante. De otro lado, en una de las formas especiales de legitimación se prevé la posibilidad de que la demanda sea formulada por asociaciones que tengan por finalidad proteger al consumidor de acuerdo con sus estatutos. En tal caso, los consumidores, aunque no actuarían de manera individual, si estarían representados de alguna forma en el proceso.

Sin embargo, estas posibilidades de comparecer al proceso operan únicamente cuando es el consumidor o la respectiva asociación quien promueve la demanda. De tal suerte que, si esta llega al juez a través de un empresario, los consumidores no van a ser vinculados al proceso ni de manera directa ni representados por una asociación. De cualquier forma, la realidad muestra que dichas posibilidades de comparecer al proceso son letra muerta, pues estos nunca son promovidos por los consumidores ni por asociaciones, sino por empresarios afectados por los actos de competencia desleal ${ }^{36}$.

En lo que tiene que ver con la legitimación por pasiva, de acuerdo con el artículo 22 de la LCD "las acciones previstas en el artículo 20 procederán contra cualquier persona cuya conducta haya contribuido a la realización del acto de competencia desleal". En tal sentido, si un consumidor colabora con la comisión de la conducta desleal también podría estar llamado a intervenir en un proceso, aunque lo haría como demandado, no siendo ese, por obvias razones, el supuesto de interés en este trabajo.

Finalmente, el CGP contempla en los artículos 60 a 72 varias normas sobre intervención de litisconsortes y terceros que habilitarían la posibilidad de participación de consumidores individualizados en el proceso de competencia desleal. Pensemos, por ejemplo, que por un acto de confusión los intereses económicos de un consumidor y de un empresario se ven afectados, caso en el cual mediante un litisconsorcio facultativo (art. 60 del CGP) podrían presentar juntos la demanda.

Bajo estas figuras, el consumidor podría tener intervención dentro del proceso, aunque actuaría como parte, como puede verse en la mayoría de ellas. Sin embargo, la situación es diferente cuando el proceso de competencia desleal se desarrolla entre empresarios — como se desarrollan normalmente todos los procesos de este tipo-, pues, en ese caso, ninguna de las formas de intervención ofrece la posibilidad de llamar a la comunidad de consumidores para ser escuchados en defensa de sus derechos. El proceso se desarrolla estrictamente inter partes, únicamente entre los empresarios que constituyen la parte demandante y la parte demandada, a pesar de ser los consumidores potenciales afectados en la etapa preliminar (el escenario cautelar) y en la etapa definitiva (el escenario de la sentencia), tal como lo vimos en los ejemplos trabajados en capítulos 
anteriores. Todo ello permite afirmar que, si el proceso se desarrolla entre empresarios, no existen normas especiales sobre intervención que garanticen la comparecencia de los consumidores al proceso.

Partiendo de lo dicho, es que se echa de menos la existencia de una norma que facilite la presencia de los consumidores a través de quien pudiera representar sus intereses dentro de un proceso de competencia desleal; y aunque esta posibilidad podría resultar extraña en un proceso con efectos, en principio inter partes, lo cierto es que no es ajena a nuestro sistema legal.

En efecto, un ejemplo cercano lo ofrece la regulación en materia de acciones populares contenida en la Ley 472 de 1998 - interesada también en la protección de la libre competencia económica y los derechos de los consumidores-, la cual establece en el artículo 21 que "si la demanda no hubiere sido promovida por el Ministerio Público se le comunicará a éste el auto admisorio de la demanda, con el fin de que intervengan como parte pública en defensa de los derechos e intereses colectivos, en aquellos procesos que lo considere conveniente" ${ }^{\text {37 }}$. Sobre esta intervención explica Guayacán que:

\footnotetext{
"si examinamos antecedentes históricos en nuestra tradición, encontramos en el Digesto la indicación al magistrado según la cual entre varios actores populares se elige al más idóneo, y se privilegia a quien tenga un interés propio, quizás porque se considera que ello garantiza un mayor compromiso en la defensa del interés colectivo. Vemos aquí un directo antecedente de control, o si se prefiere, de garantía de la representatividad adecuada que nuestra legislación vigente mantiene en su artículo 21, cuando establece que deberá informarse al ministerio público a fin de que intervenga como parte pública en defensa de los derechos e intereses colectivos, y que se le dará aviso a la entidad administrativa encargada de proteger el derecho colectivo afectado.". ${ }^{38}$
}

Así, esta regulación especial ofrece un interesante y apropiado ejemplo que ilustra acertadamente sobre la posibilidad de que los consumidores cuenten con representación en un proceso judicial, la cual, adecuada mutatis mutandi a los procesos judiciales por actos de competencia desleal, garantizaría la protección de los derechos de estos agentes del mercado frente a la posible frustración de los beneficios que genera la libre competencia económica.

\section{Dentro de los requisitos para el decreto de una medida cautelar, de acuerdo con las disposiciones especiales de la Ley 256 de 1996, no se incluye la verificación de una posible afectación a los consumidores. Por tanto, es esa una variable que no contempla el juez especializado}

La LCD, en su artículo 31, contiene una regulación especial en materia de medidas cautelares como ya antes fue mencionado. Así, dicha norma se refiere a la apariencia de buen derecho, asociada a la comisión de la conducta o su inminencia. Igualmente, se establece la necesidad de que sea solicitada por quien goce de legitimación y las órdenes que pueden requerirse al juez. En seguida, la disposición establece el trámite preferente de la medida cautelar y la posibilidad de decretarla sin oír a la contraparte en caso de que exista un peligro grave e inminente, lo cual puede hacer el juez en el término de 24 horas. Más adelante, queda habilitada la posibilidad de solicitar las medidas antes de la presentación de la demanda y la competencia territorial del juez.

De esta manera, la norma especial contiene una serie de requisitos para que pueda ser decretada la medida cautelar y algunos aspectos asociados al procedimiento. Sin embargo, ninguno de sus apartes impone al juez el deber de estudiar, o al menos considerar, la posibilidad de que con la medida pueda producirse un efecto negativo que impacte a los consumidores, aun a pesar de la incidencia del régimen de competencia desleal sobre la libre competencia económica.

De hecho, al estudiar cada una de las decisiones cautelares recopiladas para hacer este trabajo, pudo verificarse que, efectivamente, en ninguna de ellas el juez de competencia desleal incluyó un acápite dedicado a analizar si la medida cautelar podía afectar a los consumidores como beneficiarios de la libre competencia 
económica. Si el funcionario contara con la posibilidad de incluir dicha variable como uno de sus "criterios orientadores", podría negarse a decretar la medida o diseñar una con un alcance que no trascienda la esfera particular de los vinculados al proceso.

\section{Las cauciones que se constituyen dentro de un proceso judicial por actos de competencia desleal no benefician a los consumidores}

El artículo 590 del CGP en su numeral 2 condiciona el decreto de las medidas cautelares a la constitución de una caución. Las cauciones están concebidas como un mecanismo de garantía a favor de quien ha sido afectado con una orden cautelar, pues su propósito es el de resarcir los daños ocasionados con la práctica de esta. Al respecto explica Azula que:

"el Código General del Proceso, en su libro cuarto, título II, regula las cauciones, pues constituyen uno de los requisitos para la viabilidad de determinadas actuaciones. En sí consideradas, son una garantía que responde de los perjuicios ocasionados con determinadas actuaciones. La caución, pues, es un requisito para la viabilidad de un acto, porque sin ella no puede llevarse a cabo, pero que se hace efectiva solo en el supuesto de que con él se produzcan los 'efectos dañosos". 39

La norma mencionada no especifica que la caución se constituye exclusivamente a favor de la parte demandada, por lo que podría concluirse que los terceros también pueden ser beneficiaros de ellas. Dicho aspecto puede confirmarse con la explicación de Devis Echandía quien afirmó que estas garantías "deben otorgarse en el curso de procesos o en ciertas diligencias previas a estos, para responder por los perjuicios que se causen a las partes o a terceros" $\$ 0$.

Sin embargo, las cauciones que se constituyen para garantizar el pago de los daños que ocasionan las medidas cautelares decretadas en asuntos de competencia desleal, no están diseñadas para beneficiar a los consumidores.

Para explicarlo, lo primero que puede destacarse es que, si los consumidores no son vinculados por ninguna vía al proceso judicial por actos de competencia desleal que tiene lugar entre empresarios, ni su posible afectación es considerada al momento de decretar la medida cautelar, entonces el juez tampoco cuenta con ningún elemento de juicio que le permita incluirlos como beneficiarios de la caución. Cabe señalar que en la revisión de las decisiones sobre medidas cautelares analizadas pudo establecerse que en todas ellas la constitución de la caución se ordenó a favor de la parte demandada, sin que en ninguno de los casos se mencionara a los consumidores como beneficiarios de la garantía.

En segundo lugar, es claro que sería imposible para los consumidores promover un incidente para la liquidación de los perjuicios causados por una medida cautelar, debido a que, si nunca son invitados a vincularse al proceso, no podrían estar al tanto de los términos y oportunidades para promover tal actuación procesal, lo que confirma que las cauciones no están diseñadas para beneficiarlos.

En tal sentido, las cauciones, como mecanismo de garantía para el pago de los daños causados con la práctica de medidas cautelares que se decretan en procesos judiciales por actos de competencia desleal entre empresarios, no están destinadas a beneficiar a los consumidores.

\section{Conclusión}

La libre competencia económica se concibe desde una doble dimensión, pues funciona en beneficio de los empresarios y en beneficio de los consumidores, quienes gracias a ella acceden a productos y servicios con mayor calidad y a mejores precios. Para lograrlo, es fundamental garantizar la pluralidad de oferentes, pues así se garantiza la libre elección y se promueve la eficiencia. 
Las medidas cautelares innominadas, proferidas en procesos de competencia desleal, podrían trascender la esfera particular de las partes vinculadas al proceso hasta impactar negativamente a los consumidores, debido a la posible frustración de los beneficios esperables de la libre competencia económica. Esa afectación que, en principio, debe ser soportada por los consumidores por ser el resultado de una decisión legítima del juez, se torna problemática cuando son desestimadas las pretensiones de la demanda al ser dictada la sentencia, pues, en ese caso, la decisión cautelar puede haber causado una doble afectación: la que posiblemente sufre el cautelado y la que posiblemente sufren los consumidores, quienes, a esa altura, habrán padecido un daño que no tenían qué soportar y que, por tanto, merece resarcimiento. Pese a lo dicho, tal problemática no es de interés para la LCD, ni para el CGP.

\section{Referencias}

Andrea Meroi, Tipología, clases y finalidad de la pretensión cautelar, en Tratado de las medidas cautelares, 117-217 (Carlos Camps dir., Abeledo Perrot, 2012).

Constitución Política de Colombia [Const]. 7 de julio de 1991 (Colombia).

Corte Constitucional de Colombia. Sentencia C-150 de 2003 (M. P. Manuel José Cepeda Espinosa; 25 de febrero de 2003).

Corte Constitucional de Colombia. Sentencia C-228 de 2010 (M. P. Luis Ernesto Vargas Silva; 24 de marzo de 2010).

Corte Constitucional de Colombia. Sentencia C-389 de 2002 (M. P. Clara Inés Vargas Hernández; 22 de mayo de 2002).

Corte Constitucional de Colombia. Sentencia C-615 de 2002 (M. P. Marco Gerardo Monroy Cabra; 8 de agosto de 2002).

Corte Constitucional de Colombia. Sentencia C-616 de 2001 (M. P. Rodrigo Escobar Gil; 13 de junio de 2001).

Corte Constitucional de Colombia. Sentencia C-815 de 2001 (M. P. Rodrigo Escobar Gil; 2 de agosto de 2001).

Corte Constitucional de Colombia. Sentencia de tutela T-583 de 2003 (M. P. Jaime Córdoba Triviño; de 17 de julio de 2003).

Delio Gómez Leyva, De las restricciones, del abuso y de la deslealtad en la competencia económica (Cámara de comercio de Bogotá, 1998).

Edgardo Villamil Portillla, Teoría Constitucional del Proceso (1a.ed., Ediciones Doctrina y Lley Ltda., 1999).

Eduardo García Sarmiento, Jeannette García Olaya, Medidas cautelares: Introducción a su estudio (2a. ed., Temis, 2005).

Eduardo J. Couture, Fundamentos del derecho procesal civil (3a. ed., Roque de Palma Editor, 1958).

II Enrico Redenti, Derecho Procesal Civil. El sistema de las impugnaciones de las sentencias. Procedimientos especiales de cognición y cautelares. Procedimientos de ejecución (Ediciones Jurídicas Europa-América, 1957).

II Jaime Azula Camacho, Manual de derecho procesal Parte General (9a. ed., Temis, 2015).

III Hernando Devis Echandía, Compendio de Derecho Procesal. El Proceso Civil Parte General (8a. ed., Biblioteca Jurídica Dike, Medellín, 1994).

Jorge Forero Silva, Medidas cautelares en el Código General del Proceso (3a.ed., Temis, 2018).

José Fernando Sandoval, Medidas cautelares en procesos de competencia desleal y en acciones por infracción de derechos de propiedad industrial, ¿un camino hacia el prejuzgamiento?, 43 Revista del Instituto Colombiano de Derecho Procesal, 153-176 (2016). http://publicacionesicdp.com/index.php/Revistas-icdp/article/view/408/pdf

José Massaguer, Comentario a la ley de competencia desleal (1a.ed., Civitas Ediciones, 1999).

Juan Carlos Guayacán, La acción popular, la acción de grupo y las acciones colectivas. Comparación de algunos tópicos entre el ordenamiento colombiano y el Anteproyecto de Código Modelo de procesos colectivos para Iberoamérica, Revista de Derecho Privado Universidad Externado de Colombia, n. ${ }^{\circ}$ 9, 35-56 (2005). https://revistas.uexternado.edu .co/index.php/derpri/article/view/594/560 
Juan Ignacio Font Galán, Constitución Económica y Derecho de la Competencia (Ed. Tecnos, 1987).

Ley 1564 de 2012. Por medio de la cual se expide el Código General del Proceso y se dictan otras disposiciones. 12 de julio de 2012. D.O. No. 48489.

Ley 256 de 1996. Por la cual se dictan normas sobre competencia desleal. 18 de enero de 1996. D.O. No. 42692.

Ley 472 de 1998. Por la cual se desarrolla el artículo 88 de la Constitución Política de Colombia en relación con el ejercicio de las acciones populares y de grupo y se dictan otras disposiciones. 6 de agosto de 1998. D.O. No. 43357.

Manuel Ortells Ramos, Las medidas cautelares (La Ley, 2000).

Paul Nihoul, Introducción al derecho de la competencia. Posición de las autoridades, de los consumidores y de las empresas (1..ed., Universidad Externado de Colombia, 2005).

Piero Calamandrei, Introducción al estudio sistemático de las providencias cautelares (ARA Editores, 2005).

Superintendencia de Industria y Comercio de Colombia. Auto No. 1269 de 25 de enero de 2013.

Superintendencia de Industria y Comercio de Colombia. Auto No. 12433 de 20 de marzo de 2014.

Superintendencia de Industria y Comercio de Colombia. Auto No. 16399 de 1 de abril de 2014.

Superintendencia de Industria y Comercio de Colombia. Auto No. 22646 de 6 de mayo de 2014.

Superintendencia de Industria y Comercio de Colombia. Auto No. 24759 de 9 de agosto de 2013.

Superintendencia de Industria y Comercio de Colombia. Auto No. 2712 de 15 de febrero de 2013.

Superintendencia de Industria y Comercio de Colombia. Auto No. 3689 de 28 de febrero de 2013.

Superintendencia de Industria y Comercio de Colombia. Auto No. 3712 de 28 de febrero de 2013.

Superintendencia de Industria y Comercio de Colombia. Auto No. 38303 de 13 de diciembre de 2013.

Superintendencia de Industria y Comercio de Colombia. Auto No. 53658 de 16 de diciembre de 2014.

Superintendencia de Industria y Comercio de Colombia. Sentencia de 18 de diciembre de 2014.

Superintendencia de Industria y Comercio de Colombia. Sentencia de 4 de agosto de 2015.

Ugo Rocco, Tratado de Derecho Procesal Civil: Parte especial, proceso cautelar (Ed. Temis, 1977).

Vicente Pérez Daudí, Las medidas cautelares en el proceso civil (Atelier Libros jurídicos, Barcelona, 2012).

\section{Notas}

1 Delio Gómez Leyva, De las restricciones, del abuso y de la deslealtad en la competencia económica, 40 (Cámara de comercio de Bogotá, 1998).

2 Corte Constitucional de Colombia. Sentencia C-616 de 2001 (M. P. Rodrigo Escobar Gil; 13 de junio de 2001). En este mismo sentido pueden consultarse las sentencias de la Corte Constitucional C-615 de 2002 y T-583 de 2003

3 Corte Constitucional de Colombia. Sentencia C-815 de 2001 (M. P. Rodrigo Escobar Gil; 2 de agosto de 2001); Corte Constitucional de Colombia. Sentencia C-389 de 2002 (M. P. Clara Inés Vargas Hernández; 22 de mayo de 2002). En este mismo sentido puede consultarse la sentencia de la Corte Constitucional de Colombia. Sentencia C-228 de 2010 (M. P. Luis Ernesto Vargas Silva; 24 de marzo de 2010).

4 Corte Constitucional de Colombia. Sentencia C-150 de 2003 (M. P. Manuel José Cepeda Espinosa; 25 de febrero de 2003 ).

5 Juan Ignacio Font Galán, Constitución Económica y Derecho de la Competencia, 44-45 (Ed. Tecnos, 1987).

6 Corte Constitucional de Colombia. Sentencia C-815 de 2001 (M. P. Rodrigo Escobar Gil; 2 de agosto de 2001).

7 Paul Nihoul, Introducción al derecho de la competencia. Posición de las autoridades, de los consumidores y de las empresas, 34-35 (1.a ed., Universidad Externado de Colombia, 2005).

8 José Massaguer, Comentario a la ley de competencia desleal (1a.ed., Civitas Ediciones, 1999).

$9 \mathrm{Al}$ respecto ver artículos 2 y 3 de la Ley 256 de 1996. Por la cual se dictan normas sobre competencia desleal. 18 de enero de 1996. D.O. No. 42692. 
10 Las diversas conductas de competencia desleal se pueden encontrar en los artículos 7 a 19 de la Ley 256 de 1996.

11 Edgardo Villamil Portillla, Teoría Constitucional del Proceso, 882 (1a.ed., Ediciones Doctrina y Lley Ltda., 1999).

12 Por ejemplo, en materia de competencia desleal, el artículo 31 de la Ley 256 de 1996. Igualmente, en materia derechos colectivos y su protección a través de las acciones populares, el inciso tercero del artículo 17 la Ley 472 de 1998 . Por la cual se desarrolla el artículo 88 de la Constitución Política de Colombia en relación con el ejercicio de las acciones populares y de grupo y se dictan otras disposiciones. 6 de agosto de 1998. D.O. No. 43357.

13 Ley 472 de 1998. Por la cual se desarrolla el artículo 88 de la Constitución Política de Colombia en relación con el ejercicio de las acciones populares y de grupo y se dictan otras disposiciones. 6 de agosto de 1998. D.O. No. 43357.

14 Andrea Meroi, Tipología, clases y finalidad de la pretensión cautelar, en Tratado de las medidas cautelares, 199 (Carlos Camps dir., Abeledo Perrot, 2012).

15 Lo llamo artesano por el trabajo del juez de elaborar "con su destreza y su mano" la medida cautelar más ajustada a las necesidades del caso, como cuando un alfarero elabora una vasija con un diseño especial para atender las necesidades de su cliente.

16 Una denominación similar fue utilizada en el artículo: José Fernando Sandoval, Medidas cautelares en procesos de competencia deslealy en acciones por infracción de derechos de propiedad industrial, ¿un camino hacia el prejuzgamiento?, 43 Revista del Instituto Colombiano de Derecho Procesal, 153-176 (2016).

17 Eduardo García Sarmiento, Jeannette García Olaya, Medidas cautelares: Introducción a su estudio, 24 (2a. ed., Temis, 2005).

18 Ugo Rocco, Tratado de Derecho Procesal Civil: Parte especial, proceso cautelar, 48 (Ed. Temis, 1977).

19 Vicente Pérez Daudí, Las medidas cautelares en el proceso civil, 66 (Atelier Libros jurídicos, Barcelona, 2012).

20 Piero Calamandrei, Introducción al estudio sistemático de las providencias cautelares, 77 (ARA Editores, 2005).

21 II Enrico Redenti, Derecho Procesal Civil. El sistema de las impugnaciones de las sentencias. Procedimientos especiales de cognición y cautelares. Procedimientos de ejecución, 77 (Ediciones Jurídicas Europa-América, 1957).

22 Como es el caso de los procesos judiciales de competencia desleal.

23 Eduardo J. Couture, Fundamentos del derecho procesal civil, 51 (3a. ed., Roque de Palma Editor, 1958).

24 Manuel Ortells Ramos, Las medidas cautelares, 134 (La Ley, 2000).

25 Jorge Forero Silva, Medidas cautelares en el Código General del Proceso, 32-33 (3a.ed., Temis, 2018).

26 Todas las decisiones estudiadas corresponden a providencias judiciales proferidas por la Superintendencia de Industria y Comercio de Colombia, teniendo en cuenta que es la entidad administrativa a la que, debido a su especialidad, le fueron otorgadas funciones jurisdiccionales en materia de competencia desleal.

27 Superintendencia de Industria y Comercio de Colombia. Auto No. 1269 de 25 de enero de 2013.

28 Superintendencia de Industria y Comercio de Colombia. Auto No. 3712 de 28 de febrero de 2013.

29 Superintendencia de Industria y Comercio de Colombia. Auto No. 12433 de 20 de marzo de 2014.

$30 \mathrm{Al}$ respecto se pueden revisar: Superintendencia de Industria y Comercio de Colombia. Auto No. 2712 de 15 de febrero de 2013; Auto No. 24759 de 9 de agosto de 2013; Auto No. 16399 de 1 de abril de 2014; Auto No. 22646 de 6 de mayo de 2014; Auto No. 53658 de 16 de diciembre de 2014.

31 Superintendencia de Industria y Comercio de Colombia. Auto No. 38303 de 13 de diciembre de 2013.

32 Superintendencia de Industria y Comercio de Colombia. Sentencia de 4 de agosto de 2015.

33 Tenga en cuenta el lector que esto corresponde a un ejercicio hipotético sobre daños que podrían derivarse de los casos que se están estudiando, acudiendo para ello a tipologías tradicionales.

34 Superintendencia de Industria y Comercio de Colombia. Auto No. 3689 de 28 de febrero de 2013. 
35 Superintendencia de Industria y Comercio de Colombia. Sentencia de 18 de diciembre de 2014.

36 Dentro de las providencias estudiadas para efectos de elaborar el presente artículo, correspondientes a decisiones acerca de medidas cautelares dentro de los años 2012 a 2017, pudo observarse que en ninguna de ellas la acción era promovida por consumidores o por asociaciones cuya finalidad fuera la protección de sus derechos.

37 Resaltado del autor de este artículo.

38 Juan Carlos Guayacán, La acción popular, la acción de grupo y las acciones colectivas. Comparación de algunos tópicos entre el ordenamiento colombiano y el Anteproyecto de Código Modelo de procesos colectivos para Iberoamérica, Revista de Derecho Privado Universidad Externado de Colombia, n. ${ }^{\circ}$ 9, 46 (2005).

39 II Jaime Azula Camacho, Manual de derecho procesal Parte General, 419 (9a. ed., Temis, 2015).

40 III Hernando Devis Echandía, Compendio de Derecho Procesal. El Proceso Civil Parte General, 479 (8a. ed., Biblioteca Jurídica Dike, Medellín, 1994).

\section{Licencia Creative Commons CC BY 4.0}

Cómo citar este artículo: José Fernando Sandoval Gutiérrez, Medidas cautelares innominadas en procesos de competencia desleal y su capacidad de afectación a los consumidores, 69 Vniversitas (2020). https://doi.org/1 0.11144/Javeriana.vj69.mcip 